\title{
Morphometric and Ultrastructural Assessment of Bronchial Mucous Glands in Sheep Following Smoke Inhalation and Burn Injury
}

\author{
Robert A. Cox, ${ }^{*}$ Peter C. Moller, ${ }^{* *}$ Ann S. Burke, ${ }^{*}$ Abhijit Chandra, ${ }^{* *}$ Katsumi Shimoda, ${ }^{*}$ \\ Lillian D. Traber, ${ }^{* *}$ Frank C. Schmalstieg, ${ }^{* *}$ Daniel L. Traber,** and Hal K. Hawkins, ** \\ * Shriners Burns Hospital, Galveston, TX, 77550 \\ ** University of Texas Medical Branch, Galveston, TX, 77550
}

Smoke inhalation injury increases the morbidity and mortality of burn patients. Previous studies have shown that an ovine model of cooled cotton smoke inhalation injury and $40 \%$ total body surface area cutaneous burn $(\mathrm{S}+\mathrm{B})$ models the pathophysiology of these injuries in humans [1]. Initial injury from smoke inhalation is limited to the tracheobronchial airways and is characterized by epithelial cell exfoliation, mucus secretion, increased submucosal microvascular permeability and acute inflammatory cell exudation [2]. These responses promote the formation of obstructive airway casts [3]. Recent studies have shown that a major component of intrapulmonary obstructive material is mucus derived from tracheobronchial glands, and that upper airway obstructive material migrates into distal airways and parenchyma. Obstructive casts are described life threatening, and are considered important in the development of acute lung injury [4]. This study describes morphological changes in bronchial mucous glands in normal sheep and in sheep 48 hours after smoke inhalation and burn $(\mathrm{S}+\mathrm{B})$ injury.

Bronchial tissue from uninjured $(\mathrm{N}=3)$ and $\mathrm{S}+\mathrm{B}$ injured $(\mathrm{N}=3)$ sheep were sampled and processed for transmission electron microscopy (TEM) per protocol. Tissues for analysis were obtained from blocks selected randomly. Semithin sections for light microscopy were stained with toluidine blue. Thin sections were stained with uranyl acetate and lead citrate. Gland acinar area was measured in semithin sections via digital imaging (Soft Imaging Systems, Lakewood, CO). The cross-sectional areas of the first 10 acini encountered were determined and a mean acinar area was determined for each animal. Statistical software (SigmaStat, Jandel, San Rafael, CA) was used to compare acinar size between uninjured and S+B injured tissue using the Student's t test. The ultrastructure of all mucous gland cells in thin sections was recorded at 2000X, print magnification 6000X. Three observers examined the micrographs to identify morphological differences between groups.

Light microscopic morphometric analysis showed that mean acinar area in uninjured tissue was $3095.7 \pm 1183.7 \mathrm{um}^{2}$ (mean $\pm \mathrm{SD}$ ) compared to $6879.7 \pm 515.9 \mathrm{um}^{2}$ in $\mathrm{S}+\mathrm{B}$ tissue. This difference was significantly different, $\mathrm{p}=0.042$ (Fig 1). Qualitatively, glandular secretory cells appeared to contain fewer mucous granules and exhibit signs of cell injury. Ultrastructurally, a pattern of focally decreased epithelial height and sublethal cell injury was evident in secretory cells in $\mathrm{S}+\mathrm{B}$ injured tissue compared to controls. Occasional necrotic secretory cells were present in glands from injured tissue. None were observed in uninjured tissue. Focally enhanced secretory activity was evident, with prominent rough endoplasmic reticulum and mucous granules undergoing merocrine secretion. Figures $2 \mathrm{~A}$ and B are TEM micrographs showing attenuation of glandular secretory cells from a $\mathrm{S}+\mathrm{B}$ animal compared to secretory cells from a uninjured animal.

In conclusion, combined smoke inhalation and burn injury promotes secretion of mucus and dilation of acini, focal sublethal cell injury and cell necrosis. Modulation of glandular secretion might 
provide a clinical intervention strategy to inhibit secretion and resulting airway obstruction. Increased acinar area may provide a useful morphological measurement in assessment of a pharmacological agent's ability to inhibit glandular secretion. Funding for this study was provided by the Shriners of North America [5]

\section{References}

[1] D.N. Herndon et al., Resusitation 14 (1986) 43.

[2] S. Abdi et al., Am. Rev. Respir. Dis. 142 (1990) 1436.

[3] D.N. Herndon et al., J. Trauma 24 (12) (1884) 1044.

[4] C.S. Cox et al., Surg. Gynecol. Obstet. 176 (1993) 339.

[5] This study was funded by the Shriners of North America through grants to Dr. Daniel Traber, \# 8450 and to Dr. Hal Hawkins, \#8460.

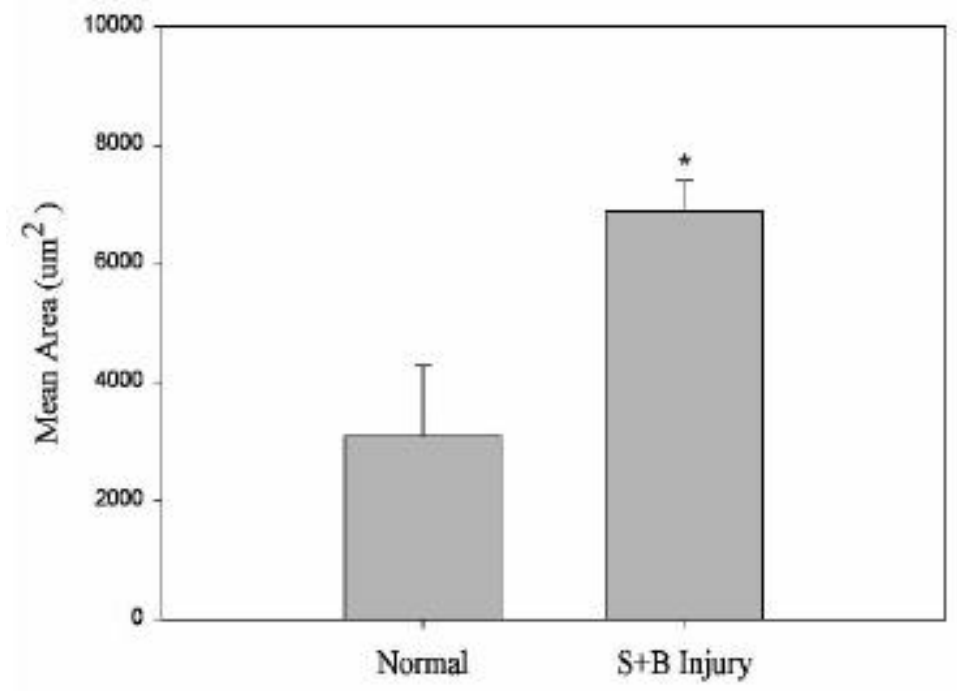

Figure 1. Bar graph showing the mean acinar area in bronchial tissue from normal and $\mathrm{S}+\mathrm{B}$ injured tissue. $*=$ statistically different from normal, $\mathrm{p}=0.042$.

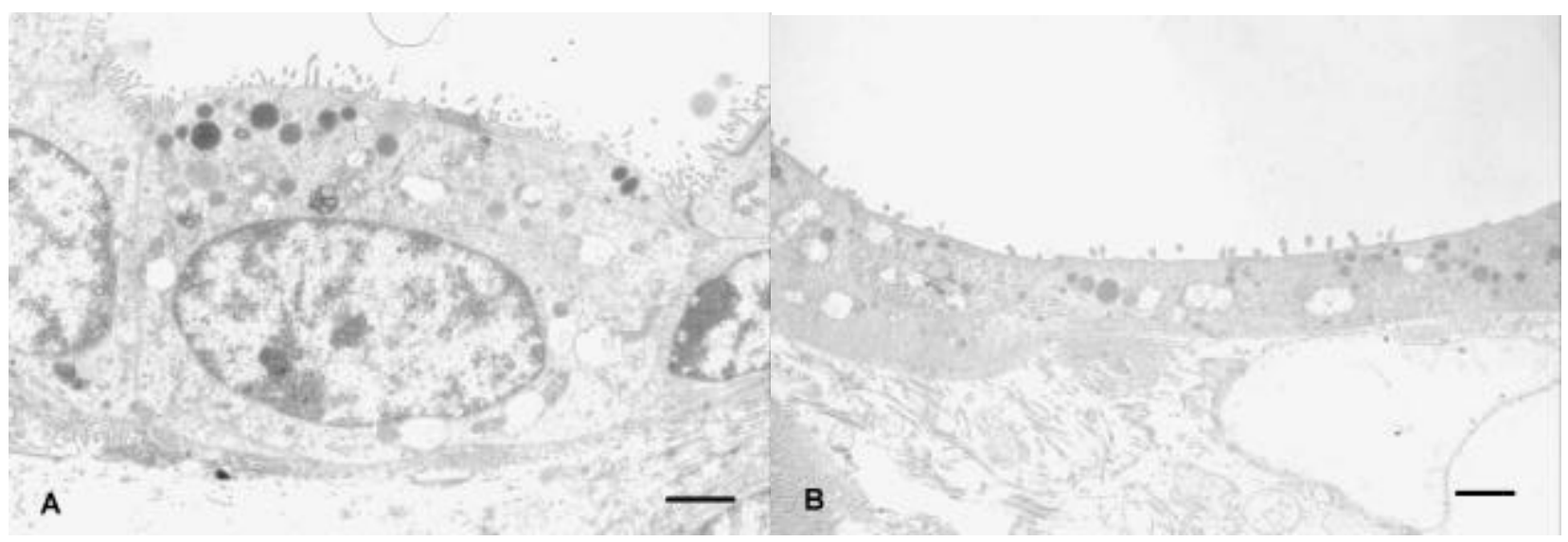

Figure 2. TEM micrographs representative of secretory cells in bronchial glands from a normal sheep (A) and from a sheep 48 hours after S+B injury (B). Bar = $1 \mathrm{um}$. 